\title{
Disulphide bond reduction of a therapeutic monoclonal antibody during cell culture manufacturing operations
}

\author{
Brian Mullan ${ }^{1 *}$, Bryan Dravis ${ }^{2}$, Amareth Lim³ $^{3}$, Ambrose Clarke ${ }^{4}$, Susan Janes ${ }^{3}$, Pete Lambooy², Don Olson², \\ Tomas O'Riordan' ${ }^{1}$, Bruce Ricart ${ }^{3}$, Alexander G Tulloch ${ }^{2}$ \\ From 22nd European Society for Animal Cell Technology (ESACT) Meeting on Cell Based Technologies \\ Vienna, Austria. 15-18 May 2011
}

\section{Background}

Disulphide bonding is critical to maintaining immunoglobulin (IgG) tertiary and quaternary structure for therapeutic monoclonal antibodies (MAb). Both inter-and intra-chain disulphide bonds are formed intracellularly in the expression host prior to secretion and purification during MAb production processes. Disulphide bond shuffling has previously been reported for $\operatorname{IgG}_{2}[1,2]$ and disulphide-mediated arm-exchange for $\operatorname{IgG}_{4}[3,4]$, reflecting innate behaviour of these IgG classes. However, atypical and significant reduction of disulphide bonds has been recently observed in $\operatorname{IgG}_{1}[5,6]$ that present significant issues for manufacturing of therapeutic MAbs.

During manufacturing of preliminary lots of a recently transferred MAb manufacturing process $\left(\mathrm{IgG}_{1}\right)$, gross disulphide bond reduction following affinity capture chromatography of clarified production bioreactor material was observed. Investigations leading to the identification of the nature of this reduction process, and process steps to mitigate against its future occurrence, are described here. The MAb was co-developed with MacroGenics, Rockville, MD.

\section{Methods}

Production Bioreactor material for downstream processing was supplied from a 16 day, fed-batch, GS-CHO culture [7]. The Production Bioreactor was a single-use (Wave System) with a 100L (full scale) or 10L (lab model) working volume. Clarified harvest intermediate (CHI) hold studies were performed in either 560L LevMix units (full scale) or 5L Braun benchtop bioreactors

\footnotetext{
* Correspondence: mullan_brian@lilly.com

${ }^{1}$ Manufacturing Science and Technology, Eli Lilly \& Co, Kinsale, Cork, Ireland Full list of author information is available at the end of the article
}

(lab model). Purification to produce Affinity Capture chromatography eluted mainstream was performed using a $20 \mathrm{~cm} \times 20 \mathrm{~cm}$ MAbselect Protein A resin (GE Healthcare) column, and an AKTA Process skid (GE Healthcare).

LC-MS analysis was performed on a Polymer Laboratories PLRP-S HPLC column and analyzed using an Agilent 1100 HPLC system coupled to an Applied Biosystems QSTAR XL mass spectrometer, following sample preparation. CE-SDS analysis was performed using a Beckman Coulter PA800 capillary electrophoresis instrument fitted with bare-fused silica capillary and UV detection at $220 \mathrm{~nm}$, following sample preparation. Microchip CE-SDS analysis was performed using a Labon-chip microanalyser (Agilent). Free thiols were quantified using Ellman's reagent. Metabolic analysis was conducted by Metabolon (Durham, NC).

\section{Results \\ Identification of disulphide reduction of IgG during Primary Recovery}

The IgG manufacturing process as transferred from the co-developing partner included a cell culture settling step following the Production Bioreactor and prior to Primary Recovery.

Disulphide bond reduction was first detected during initial development runs by routine Non-reduced (NR) CE-SDS in-process analysis after Affinity capture chromatography (data not shown). NR-CE-SDS analysis identified elevated levels of free light chain and half antibody molecules, when compared to Reference Standard.

Additional analysis, employing microchip-based NRCE-SDS methods indicated that the antibody reduction occurred during the primary recovery cell settling step 
(results not shown). This was confirmed by LC-MC analysis (results not shown). Assessment of disulphide bonding pattern and intactness by LC-MS peptide mapping identified both inter-and intra-chain disulphide scrambling (results not shown).

\section{Delineation of events leading to $\lg G$ reduction}

Initial investigations to understand process behaviour during primary recovery identified that reducing species, including free thiols (which increase over the course of the Production Bioreactor, up to $1 \mathrm{mM}$ ), were present at the end of the Production Bioreactor (Figure 1a). Dissolved oxygen was also shown to deplete during the cell settling phase following harvest (data not shown). From this, an initial working hypothesis was formed that reducing species, including free thiols, became reactive at low dissolved oxygen concentrations and led to $\operatorname{IgG}_{1}$ disulphide bond reduction.

A revised process control strategy was implemented (see below) to prevent oxygen depletion and maintain dissolved oxygen levels above a minimum level. This involved including an aerated and agitated hold for Clarified Harvest Intermediate (CHI) in the process.

Further studies identified that $\mathrm{O}_{2}$ is critical to maintaining a stable environment for oxidised (i.e., normally disulphide bonded) $\operatorname{IgG}_{1}$ in $\mathrm{CHI}$. When $\mathrm{O}_{2}$ was present, $\mathrm{IgG}_{1}$ remained intact under all conditions evaluated. Only when $\mathrm{O}_{2}$ was deliberately absent, or stripped away, would the harvest material or $\mathrm{CHI}$ demonstrate potential for reduction (Figure 1b).

\section{Metabolic behaviour of reducing intermediates}

The working hypothesis was that by maintaining sufficient levels of dissolved oxygen in the CFM, the thiol species could be reacted out (oxidised) and a stable environment for oxidised $\mathrm{IgG}_{1}$ created (Figure 1a). However, the relationship between IgG reduction and thiol redox state is not first order (Figure 1c), and the rate of thiol oxidation was found to be dependent on the source of Production Bioreactor material (i.e., varied with different harvest lots). This indicated the involvement of an additional component, potentially catalytic, which has not yet been identified in our studies. Thioredoxins have been identified as such a catalytic component by others $[5,6]$, and these need to be recycled after one redox cycle via Thioredoxin Reductase / NADP(H).

Metabolic analysis of cell and media material from Production Bioreactors indicated high levels of oxidised homocysteine and cysteine (both reactive redox molecules), which correlated with decreasing levels of folate a)

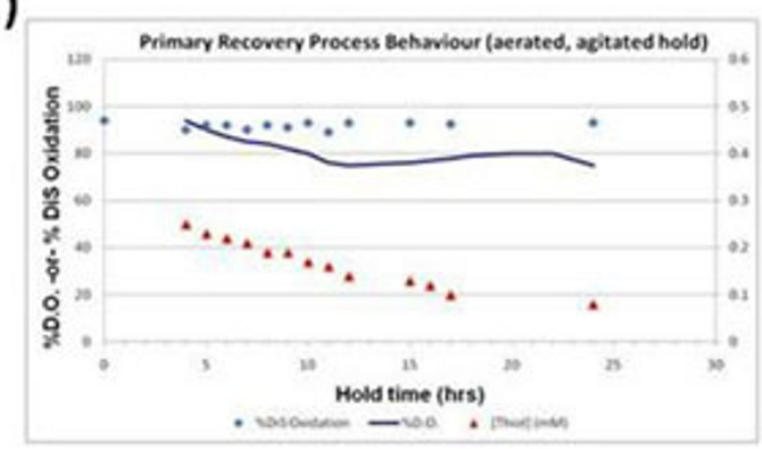

b)

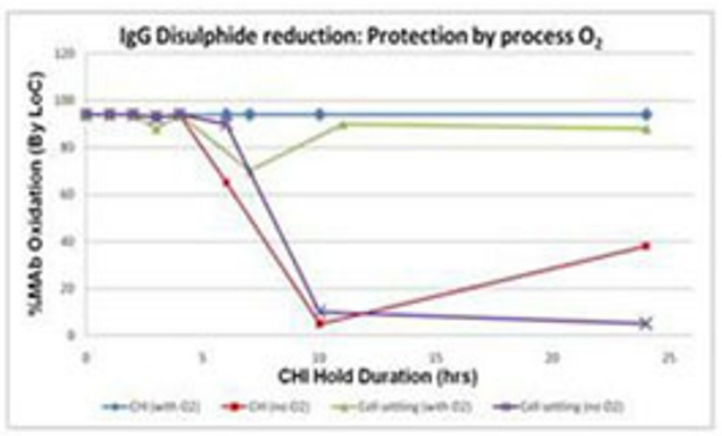

c)

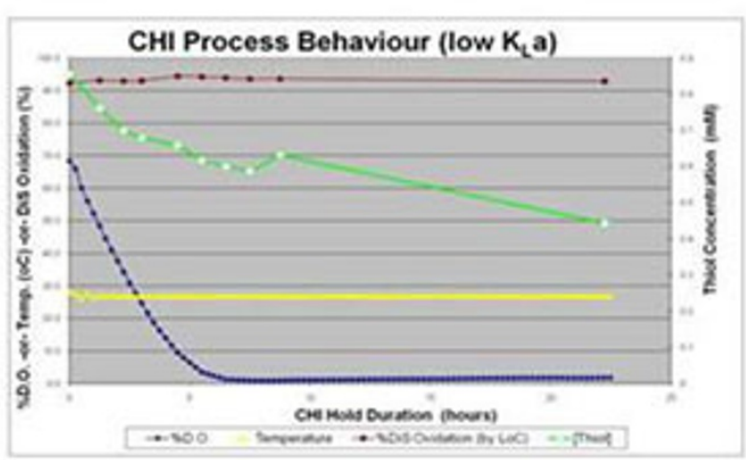

Figure $1 \mathrm{lgG}$ disulphide bond reduction under various conditions for cell-settled and immediately clarified harvest material. CHI, Clarified harvest intermediate; DiS, Disulphide; LoC, Lab-on-a-Chip (Agilent). 
(B6) and cobalamine (B12), both of which are involved in recycling homocysteine. Overall, this analysis identified numerous options for media optimisation to mitigate against IgG reduction. However, given the success of process controls (described below), and the late stage of process development (pre-validation) these media optimisation options were not pursued.

\section{Process controls to mitigate disulphide reduction of IgG}

A process control strategy was implemented including:

- Establishing a minimal dissolved oxygen level in the Production Bioreactor prior to harvesting

- Immediately clarifying the Production Bioreactor material (i.e., eliminating the cell settling step)

- Holding the CHI in a hold vessel (LevMix container, agitated hold) that had been partially pre-filled with process air.

\section{Conclusions}

- Gross disulphide bond reduction was observed during late stage development of an $\operatorname{IgG}_{1}$ monoclonal antibody being commercialised for a therapeutic indication;

- Disulphide bond reduction had a second, or higher, order link to low dissolved oxygen levels in process intermediates, and the involvement of a catalytic factor was also indicated;

- Implementation of an appropriate control strategy (and associated process analytics) informed by process development has ensured no recurrence of this issue (for $\mathrm{n}=15$ full scale lots).

\section{Author details}

${ }^{1}$ Manufacturing Science and Technology, Eli Lilly \& Co, Kinsale, Cork, Ireland. ${ }^{2}$ Bioprocess R\&D, Eli Lilly \& Co, Indianapolis, Indiana, USA. ${ }^{3}$ Bioproduct Analytical Chemistry, Eli Lilly \& Co, Indianapolis, Indiana, USA. ${ }^{4}$ Analytical Technical Operations, Eli Lilly \& Co, Kinsale, Cork, Ireland.

Published: 22 November 2011

\section{References}

1. Wypych J, et al: Human IgG2 antibodies display disulfide-mediated structural isoforms. J Biol Chem 2008, 283:16194-16205.

2. Liu YD, et al: Human lgG2 antibody disulfide rearrangement in vivo. $J$ Biol Chem 2008, 283:29266-29272.

3. van der Neut Kolfschoten M: Anti-inflammatory activity of human IgG4 antibodies by dynamic Fab arm exchange. Science 2007, 317:1554-1557.

4. Labrijn AF, et al: Therapeutic IgG4 antibodies engage in Fab-arm exchange with endogenous human IgG4 in vivo. Nature Biotechnology 2009, 27:767-773.

5. Trexler-Schmidt $M$, et al: Identification and Prevention of Antibody Disulfide Bond Reduction During Cell Culture Manufacturing. Biotechnology and Bioengineering 2010, 106:452- 461.

6. Kao Y-H, et al: Mechanism of Antibody Reduction in Cell Culture Production Processes. Biotechnology and Bioengineering 2010, 107:622-632.

7. Mullan B, et al: Transfer, Implementation and Late Stage Development of an End-To-End Single-Use Process for Monoclonal Antibody Manufacture. American Pharmaceutical Review 2011, 58-64.
doi:10.1186/1753-6561-5-S8-P110

Cite this article as: Mullan et al.: Disulphide bond reduction of a therapeutic monoclonal antibody during cell culture manufacturing operations. BMC Proceedings 2011 5(Suppl 8):P110.

\section{Submit your next manuscript to BioMed Central and take full advantage of:}

- Convenient online submission

- Thorough peer review

- No space constraints or color figure charges

- Immediate publication on acceptance

- Inclusion in PubMed, CAS, Scopus and Google Scholar

- Research which is freely available for redistribution

Submit your manuscript at www.biomedcentral.com/submit 